\title{
An empirical and descriptive study of the translation method for dubbing and subtitling
}

\author{
José Luis Martí Ferriol \\ Universitat Jaume I, Castellón
}

An Empirical and Descriptive Study of the Translation Method for Dubbing and Subtitling is the title of a doctoral thesis submitted in November 2006. This research project developed a theoretical framework where the notion of translation method was defined in terms of a graphical and parametrical representation as a function of three parameters: constraints active in audiovisual translation, translation norms and translation techniques. The object of study consisted of several independent American films shown in Spain, in dubbed and subtitled versions, in the period between 2001 and 2004. Both the preliminary and the translation phases of the translation process were taken into account in the scope of work. Empirical data were gathered through interviews with the translators of the films for the preliminary phase of the translation process; the compilation of almost 500 micro textual samples of the two translated versions provided the empirical data for the translation phase itself. The results and conclusions of the study were obtained by using rigorous statistical tools, which showed the similarities and differences between the translation methods for both the dubbed and the subtitled versions.

\section{Summary of the research project}

This piece of research was carried out with the idea of applying the Descriptive Translation Studies' approach to the field of audiovisual translation. Research in the field of translation took a turn when the conceptual postulates incorporated by the Manipulation School (Hermans, 1985) were introduced in this field of knowledge. The School's postulates (cf. infra), considered by many as being a turning point, modified the approach to translation from the 1980s onwards.

Our initial interest in this approach was mainly related to the empirical and pragmatic analysis methodology introduced by this School, i.e. a methodology based on data collection and its study, with the intention of deriving norms or recurring patterns in the translation process. We understand these norms from a descriptive standpoint as behavioural patterns rather than as a manifestation of a certain "social correctness".

Audiovisual texts are mostly characterised by their multidisciplinary specificity. Although it is still the verbal texts that are translated, the many constraints around them have to be kept in mind, since they very often end up determining the translation solutions. As a consequence, audio- 
visual translation constraints must be included in a study like ours. The third parameter that we take into consideration for the project (together with norms and constraints) is translation techniques, which should provide us with information about the solutions chosen by the translator to solve specific micro textual problems.

The main contribution of this research resides in combining the three parameters mentioned above, with a proposal for a graphical and parametrical representation for the translation method. Thus, we postulate that the translation method can be represented as a combination of these parameters which, of course, have to be taken into account for the preliminary phase of translation as well as for the translation phase itself.

As object of study, we found it appropriate to choose a group of films and analyze them in depth from a descriptive standpoint, by comparing both their dubbed and subtitled versions. The corpus consisted of five independent American films, released in the period 2001-2003. The corpus was selected following some specific criteria ${ }^{1}$, based on the underlying idea that films belonging to the (sub)genre of American independents should highlight the different translation methods for the two translated versions (the dubbed one and the subtitled one) more easily than randomly chosen productions. The five films were: Monsters' Ball (Marc Foster 2001), In the Bedroom (Todd Field 2001), The Hours (Stephen Daldry 2002), Elephant (Gus van Sant 2003) and Lost in Translation (Sophia Coppola 2003).

The fact that the films were available on DVD format not only made the research easier, but also oriented it. The different activities involved, i.e. film visualization, sample identification, data gathering and transfer to a database in the computer, could all be carried out in the same system, in a quick and integrated fashion.

\section{Objectives}

The overall objectives of this study can be summarized as follows:

- to describe the translation method (understood as the result of the presence of certain translation norms and translation techniques) used in a corpus of five films with empirical data and statistical tools;

- to demonstrate that the translation method is different in the instance of a translation for dubbing and a translation for subtitling. Researchers and professional translators in this particular field accept this state of affairs implicitly, but it has been our task to prove it with empirical data;

- to find out whether the specific translation constraints that influence translation for dubbing and translation for subtitling call for specific 
translation solutions, which materialize in an associated different translation method;

- to carry out an in-depth revision of the concept of the translation method, as well as the three evaluation parameters considered: constraints of audiovisual translation, translation norms and translation techniques. This objective calls for the elaboration of a taxonomy for each of the three parameters;

- $\quad$ to use statistics as a methodological tool to draw conclusions objectively. We consider this component to be an objective of the study as well, since no published bibliography has been found which presents normality and hypotheses tests for the evaluation of the empirical data obtained from translations.

\section{Theoretical framework and classifications for the parameters}

This article must be located within those research studies that concentrate on the 'product' as a result of translation, versus those which are more centred on the 'process' of translation (Chaume 2003, 2004). The approach, to put it more precisely, is based on the specificity of the audiovisual text in terms of discourse mode and textual configuration as a sign combination, i.e. a construct whose specificity consists of a conjunction of image and words (Chaume 1994: 139-145). The constraints inherent to AVT are therefore the focus of the attention and a fundamental parameter of analysis for the differentiation between dubbing and subtitling.

We follow the premises presented by descriptivism in the sense that the study is based on the target text. This approach supports the abovementioned analysis based on the three parameters of constraints, translation norms and translation techniques.

Toury $(1980,1995)$ approaches the descriptive study of translation as an activity governed by norms, whilst considering the adequacy or acceptability of the translation in the target culture to be the initial and most important norm. In the present study, norms are understood as behavioural patterns, but it is not our intention to carry out any kind of social assessment of this concept. Because of this, we do not understand norms as a result of a so-called "social correctness". sification of norms in audiovisual translation, in Toury's terms, both for the preliminary phase and for the translation phase itself.

The approach followed is also similar to that suggested by Delabastita (1990), who recommends studying audiovisual translation within the framework of the Polysystem Theory. As the bibliography with this article shows, there are several authors who try to apply the methodology proposed by descriptive studies to audiovisual translation in a general sense (Delabastita 1990 and Karamitroglou 2000, amongst others), however, there are only a few (Goris 1993; Chaves 2000; Ballester 2001) who really strive to im- 
plement a practical application of the general concepts mentioned in this theory to specific problems.

My classification of audiovisual translation norms and their definitions for the translation phase (the translation process itself), based on the contributions by the scholars mentioned above, is listed below:

- Linguistic Standardization: neutralization (or levelling) of the non-standard characteristics of the different English language dialects, including social dialects and idiolects;

- Naturalization: adaptation of aspects such as graphic signs, pronunciation, socio-cultural references, and especially visual synchrony (fitting), clearly affected by shooting;

- Explicitation: used for vague or unclear expressions, for connectors and logical connections. It also includes the addition of internal references to reinforce the homogeneity of the story structure, and the textual explicitation of images;

- Linguistic Fidelity: like for instance maintaining the same uncomplicated grammatical structures as in the source text;

- Euphemization: change or alteration of the 'ethical sign', making it softer (not so 'blunt' as in the source text);

- Disphemization: change or alteration of the 'ethical sign', making it harder (more explicit than in the source text).

Additionally, some macro textual conventions are to be followed by the translator once the translation assignment is accepted, be it for dubbing or subtitling (time available, usage of style books, fees, etc.). These conventions are to be understood as translation norms for the preliminary phase.

As far as translation techniques are concerned, that is, the second parameter to be considered in our model, the taxonomy proposed is supported by a thorough review of the contributions made by many scholars in the course of Translation Studies history (Chesterman 1997; Hurtado 2001; Munday 2001; Marco 2004), more particularly in the field of audiovisual translation (Delabastita 1990; Chaves 2000; Martí Ferriol 2003; Chaume 2005).

Figure 1 shows the translation technique compilation developed by the author and used in this project. 
TRANSLATION TECHNIQUE CLASSIFICATION ACCORDING TOTHE TRA NSLA TION M ETHOD

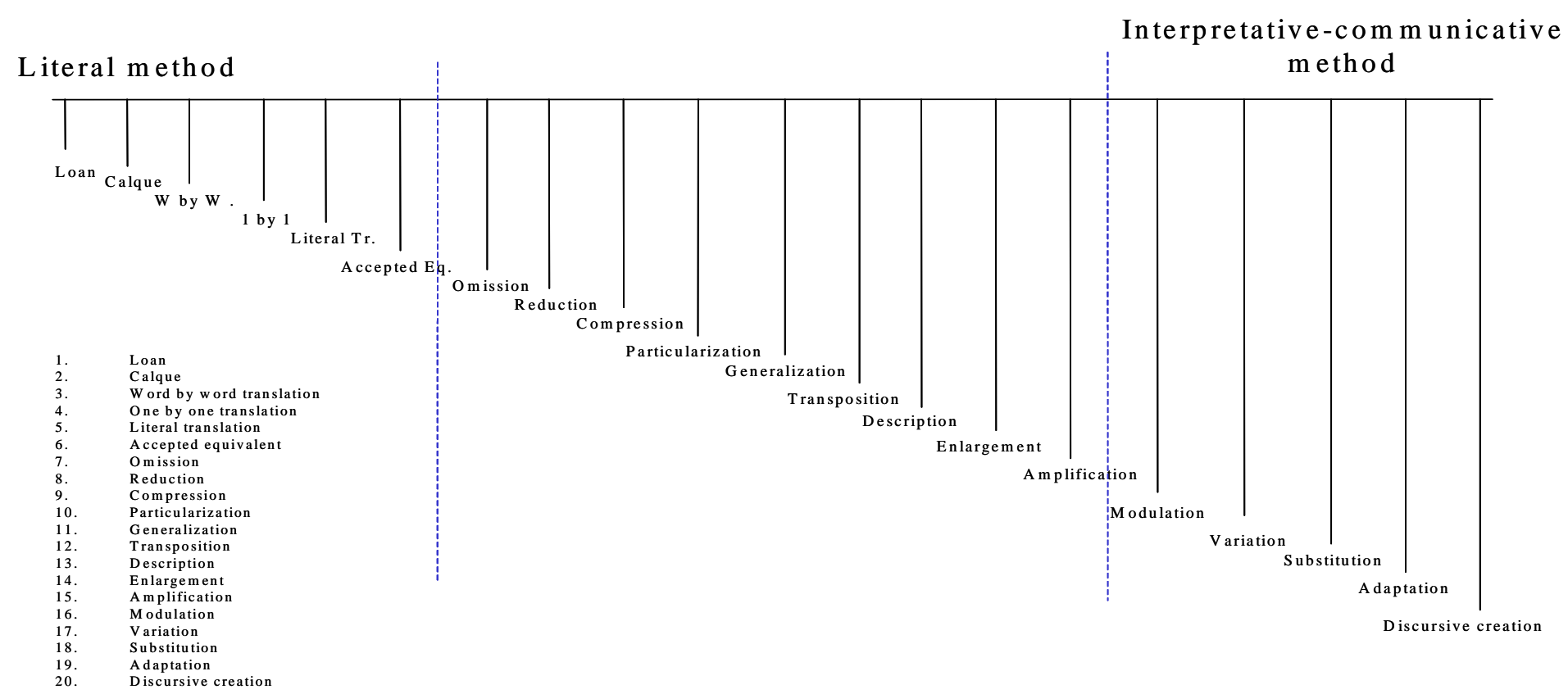

Figure 1: Translation techniques arranged according to the translation method 
The arrangement proposed is based on the translation method itself: the techniques that tend to produce a more 'literal' method are located on the left-hand side of the graph. The techniques that are aimed at producing a more 'interpretative-communicative' method are situated on the right-hand side. Note that there are also a set of intermediate techniques, which are characterized by their 'neutral' or 'linguistic' fashion, and which lie in the central portion of the graph.

At the outset of this paper we pointed out that the presence of constraints is a central feature of AVT. This is why constraints constitute the third parameter in our analysis model. A constraint type list (which includes four types: formal, linguistic, iconic and socio-cultural constraints for the translation phase) therefore also had to be generated in order to study and characterize the samples gathered during the project from this prespective. This new classification was based on contributions by Titford (1982), Mayoral et al. (1988), Whitman (1992), and Chaume (2003). In principle, these four constraint types could all play a part in dubbing as well as in subtitling. Additionally, constraints in the preliminary phase ('professional' constraints) were also included in the taxonomy based on Zabalbeascoa (1996). On the basis of our own previous research (Martí Ferriol, 2003 ${ }^{3}$ ), a new kind of constraint type was conceived for the translation phase: the 'void constraint', which could be defined as a 'lack of presence (or absence) of constraints'.

A summary of the proposed constraint classification can be found in Table 1.

Table 1: Operative Constraints in Audiovisual Translation

\begin{tabular}{|c|c|c|c|}
\hline Constraint types & Definition & Examples & $\begin{array}{c}\text { Phases where they } \\
\text { appear }\end{array}$ \\
\hline Professional & $\begin{array}{l}\text { Imposed by the work conditions a } \\
\text { translator must meet, depending on the } \\
\text { execution of a certain assignment }\end{array}$ & $\begin{array}{l}\text { Time limitations } \\
\text { fees } \\
\text { style books } \\
\text { etc }\end{array}$ & Preliminary phase \\
\hline Formal & $\begin{array}{l}\text { Inherent to the professional techniques } \\
\text { and practices due in dubbing and } \\
\text { subtitling }\end{array}$ & $\begin{array}{l}\text {.phonetic } \\
\text { synchrony } \\
\text {. isochrony } \\
\text {.etc. }\end{array}$ & Translation phase \\
\hline Linguistic & $\begin{array}{l}\text { Associated with dialectal variation, } \\
\text { idiolects, registers, spoken language }\end{array}$ & $\begin{array}{l}\text { dialects } \\
\text { idiolects } \\
\text { registers } \\
\text { spoken language } \\
\text { etc. }\end{array}$ & Translation phase \\
\hline Semiotic (or Iconic) & $\begin{array}{l}\text { Associated with filmic language and of } \\
\text { semiotic type: related to signs } \\
\text { transmitted by both the visual channel } \\
\text { and the hearing one (songs), that belong } \\
\text { to the non-linguistic signification codes } \\
\text { (except in the case of songs) }\end{array}$ & $\begin{array}{l}\text { icons } \\
\text { photography } \\
\text { montage } \\
\text { proxemics } \\
\text {. kinetic synchrony } \\
\text { songs } \\
\text {.etc. }\end{array}$ & Translation phase \\
\hline Socio-cultural & $\begin{array}{l}\text { Due to the simultaneous existence of } \\
\text { different cultural systems in the } \\
\text { linguistic and iconic messages }\end{array}$ & $\begin{array}{l}\text { verbalized } \\
\text { cultural references } \\
\text { iconic cultural } \\
\text { references }\end{array}$ & Translation phase \\
\hline "Void" constraint & Lack (absence) of constraint & - & Translation phase \\
\hline
\end{tabular}


Our intention with the table format presentation is to highlight the influence of these constraints on both translation phases: the preliminary one and the translation phase itself.

\section{Methodology of analysis for the corpus}

The existence of a direct connection between the three parameters (norms, techniques and constraints) of our study and the translation method was investigated in an attempt to make the scope of this research project more ambitious.

The concept of 'translation method' used in this paper is to be understood as defined by scholars like Venuti (1995), Chesterman (1997) and Hurtado (2001); that is, a certain mindset in the translation process followed by the translator, be it consciously or unconsciously. Our personal contribution to the concept is based on the idea that the translation method can be correlated with the use of translation norms and translation techniques, and is also undoubtedly influenced by the existence of certain audiovisual translation constraints. Based on this assumption, we tried to investigate if there is a translation method which may be different for the dubbed and subtitled versions of the films in our corpus, based on the identification of the three said parameters.

Hurtado (2001) proposes a classification of four possible translation methods: interpretative-communicative, literal, free and philological. From the point of view of our present study, only the first two are relevant. The interpretative-communicative method intends to generate a translation which aims to produce an effect in the target culture receiver that is comparable to that produced by the original text in the source culture receiver. We associate this method with the skopos of dubbing. Subtitling seems to be more related to a literal translation method (according to the results of our previous study, Martí Ferriol 2003).

In accordance with the objectives stated above, the translation method is presented below both by means of a graphical and a parametrical representation, in which the two translation phases are considered. The graphical representation is shown in Figure 2. 


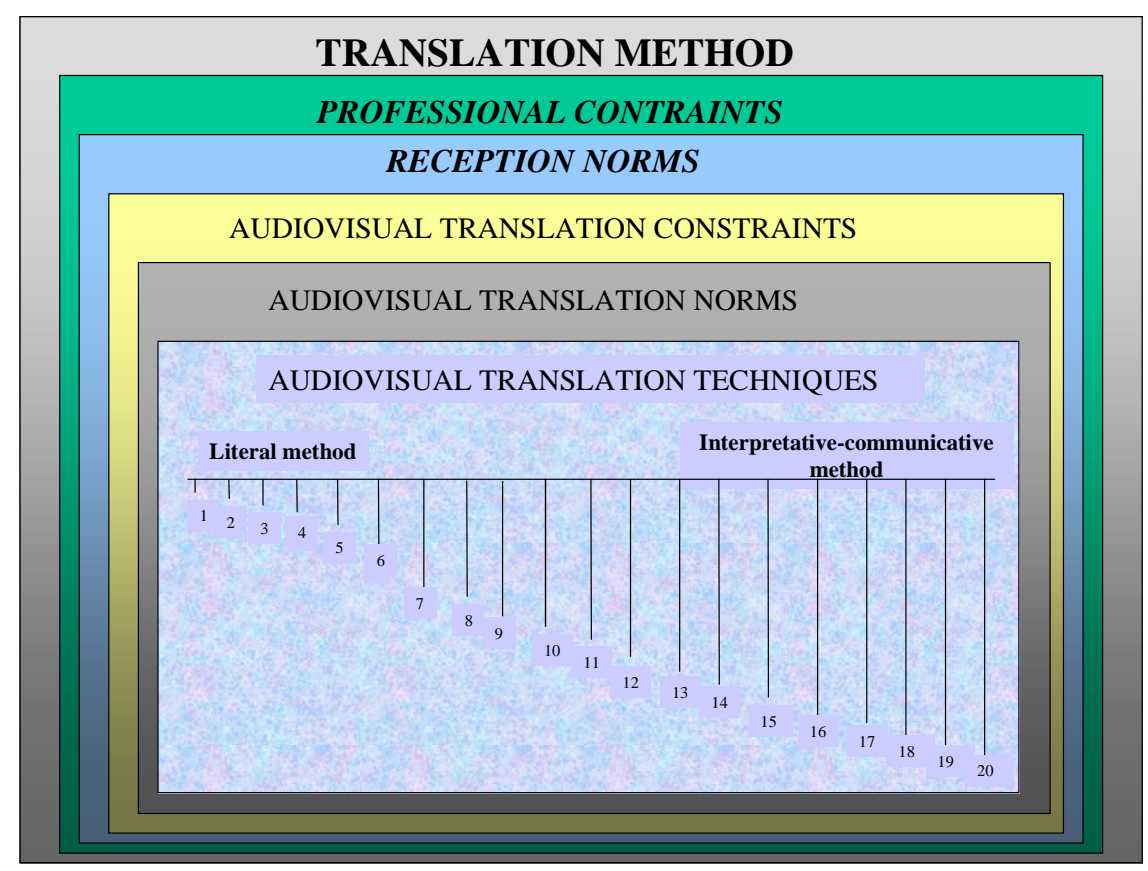

Figure 2: Graphical representation of the Translation Method

As the graphic shows, the professional constraints in the preliminary phase condition the reception norms (the macro textual conventions mentioned above), which are different for dubbing and subtitling. The constraints active in audiovisual translation influence the presence of audiovisual translation norms and translation techniques in the translation phase.

In as far as the parametrical representation is concerned, once again we consider the two same phases. Since the data gathered for these phases are of a different nature (discrete data for the preliminary phase gathered through questionnaires - see the questionnaire used in Annex 2, (Martí Ferriol 2006) - , and continuous data obtained by film descriptive analysis of the micro textual samples), the contribution of the two phases to the translation method cannot be added up in a straightforward way. Consequently, the preliminary phase only contributes to the parametrical representation of the translation method as a 'weight factor'. Formulas 1 and 2 summarize the approach. These formulas were conceived by the author of this article, in an attempt to express in a parametrical fashion how the three parameters considered in the study contribute to the concept of translation method.

(1) AVT Method = $\mathrm{f}($ Preliminary phase, Translation phase $)$

(2) AVT Method $=($ Weight Preliminary phase $) *($ Constraint $\#+$ Norm \# + (Method Coefficient * Technique \#)) 
AVT constraints and translation norms only contribute to the parametrical representation of the translation method in the translation phase through their frequency of appearance ( $\#=$ number). However, the frequency of appearance of translation techniques in the formula is graded by a coefficient ('Method Coefficient'), which takes into account the orientation of the techniques: some of them tend to produce a more interpretativecommunicative method while others generate a more literal method (cf. supra). The value of the coefficient proposed (from 1 to 20) is the one shown in the classification in Figure 1.

The 'weight' considered for the preliminary phase is assigned a value of ' 1 ', based on the input provided by the translators of the films in the corpus (seven questionnaires gathered for the ten translated texts). This means that the preliminary phase does not have a representative impact on the translation method. However, we believe that this particular aspect of the research project would probably have to be further investigated.

Since this study is descriptive and target oriented, the methodology of analysis followed for the translation phase involved starting from the target texts, that is, the dubbed and subtitled versions of the translated films, with the objective of finding examples (samples or micro textual fragments) to be analyzed. Both Spanish versions of the films were watched simultaneously in DVD format. Selected samples were then compared with the source text fragments, collected from the source text in English.

The procedure mentioned above (simultaneous watching of both target texts) proved to be very revealing, since it allowed us to identify samples that attracted our attention from a translation standpoint. It is interesting to see how both versions are almost alike in some cases, while in others they differ completely. There are many cases in which there is a fast transition from similitude to difference in the samples; this is due to the dynamics of the iconic film language, mostly associated with differences in shooting (changes of camera position).

Once a sample was selected and typed into the database, the comparison with the source text was carried out. Both Spanish translated versions (dubbed and subtitled) were compared with the source text in English. That is, the presence of constraints, their type, as well as that of norms and translation techniques, was identified, and the results were stored in an Excel database.

Parallel queries were developed for the different films to compare results for the three parameters in the two translated versions. Qualitative results are presented below.

\section{Main findings}

Although many qualitative results have been drawn in this project (for each of the three individual parameters considered), only those related to the translation method will be presented below due to space limitations ${ }^{4}$. The 
qualitative results demonstrate that a different translation method is used for dubbing versus subtitling, but only for specific constraint types operative in audiovisual translation:

- The translation method is only different in the presence of two constraint types: formal and void. When the formal or void constraints are active, the translation method for dubbing tends to be interpretative-communicative, while the method for subtitling is more literal

- $\quad$ Linguistic constraints generate similar translation methods for dubbing and subtitling. The solutions tend to naturalize the translations, using discursive creation or similar techniques

- $\quad$ Regarding iconic constraints, if we consider the specific problem of graphic codes, the translation method for subtitling is more interpretative-communicative than the one for dubbing

- No definitive conclusions could be derived for the socio-cultural constraints by the sole path of a qualitative analysis

The main question of the research study, namely, whether translation methods differ for dubbing and subtitling, was tested by using the parametrical representation introduced in the methodology chapter, and a hypotheses test (Two-sample $\mathrm{T}$ test).

The road to expressing the translation method by means of a numerical figure involved the quantification of the presence of AVT constraints, translation norms and translation techniques, for each of the dubbed and subtitled versions of the five films in our corpus. After having completed this task, we were able to summarize all the numerical data in a table, which depicted the translation method with a specific number for each of the ten translations by using the parametrical representation of the translation method. Table 2 presents this information. 
Table 2: Values obtained for the Parametrical Representation of the Translation Method in the films of our corpus

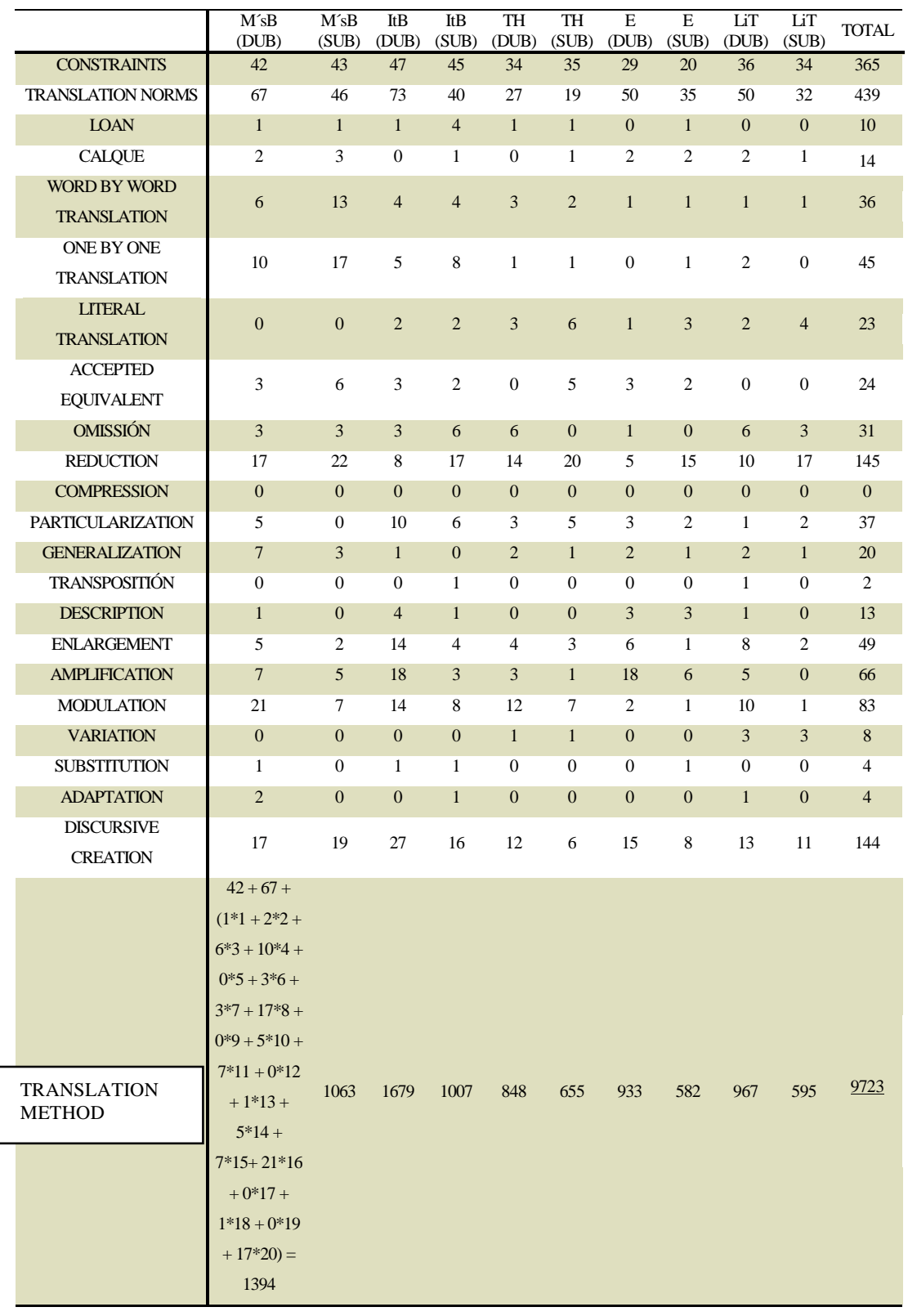


As mentioned above, statistical methods helped us check the main project objective: finding out whether the translation method is different for dubbing and subtitling. The questionnaire filled in by the translators of the films in our corpus indicated that they considered the translation method to be different in dubbing and subtitling.

Our task was, then, to see whether this statement could be proved by means of a statistically rigorous test. The test was performed using the software program Minitab ${ }^{\circledR}$ for Windows. The outcome is shown in Figure 3.

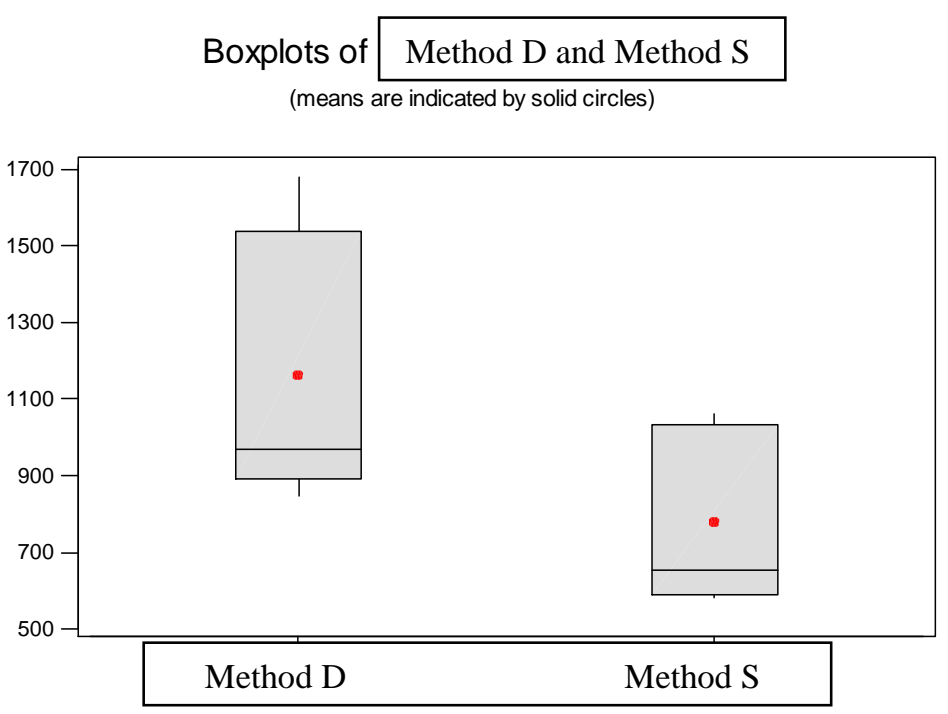

Two Sample T-Test and Confidence Interval

Two sample T Test Method in DUB vs Method in SUB

\begin{tabular}{|c|c|c|c|c|}
\hline & $\mathrm{N}$ & Mean & StDev & SE Mean \\
\hline Method D & 5 & 1164 & 357 & 160 \\
\hline Method S & 5 & 780 & 235 & 105 \\
\hline
\end{tabular}

95\% CI for mu Method D - mu Method S: ( -84; 852)

$\mathrm{T}$-Test mu Method $\mathrm{D}=\mathrm{mu}$ Method $\mathrm{S}$ (vs not $=$ ) $: \mathrm{T}=2,01$

$\mathrm{P}=0,091 \quad \mathrm{DF}=6$

Figure 3: Caption and values obtained in a Hypotheses Test for two Translation Method populations, those from the dubbed and from the subtitled versions for the five films in our corpus 
Statistically accepted conventions for a 'Two Sample T-Test' require a 'Pvalue' lower than 0.05 to confirm the hypothesis tested: in this particular case, the fact that the translation methods for dubbing and subtitling are different. The final result we obtained (0.091) was very close to the desired value (0.05), but it did not quite reach it. In statistical terms, this means that we cannot state that the translation method is really different for dubbing and subtitling with a $95 \%$ of statistical confidence. In fact, the result implies that we can only state it with a $90.9 \%$ of confidence, at least for the pilot study presented in this paper (based on the author's $\mathrm{PhD}$ thesis).

Despite the results, which mean that we should pursue this task, probably by gathering more data with an extended corpus (up to 9 films, according to some additional statistical calculations carried out during the study), the parametrical representation of the translation method proposed in our thesis looks like a promising contribution to this research field. The same comment applies, we believe, to the methodology presented in the project.

\section{Bibliography}

Ballester Casado, Ana Rosa (2001) “Doblaje y nacionalismo. El caso de Sangre y arena”. F. Chaume \& R. Agost (eds) (2001). La traducción en los medios audiovisuales. Castelló de la Plana: Publicacions de la Universitat Jaume I (Estudis sobre la traducció; 7), 165-175.

Chesterman, Andrew (1997). Memes of Translation. Amsterdam: John Benjamins.

Chaume, Frederic (1994). "El canal de comunicación en la traducción audiovisual". Trasvases Culturales: Literatura, Cine, Traducción. Gasteiz: Universidad del País Vasco-Euskal Herriko Unibertsitatea, 139-145.

Chaume, Frederic (2003). Doblatge i subtitulació per a la TV. Barcelona: Eumo Editorial.

Chaume, Frederic (2004). Cine y traducción. Madrid: Cátedra (Signo e Imagen).

Chaume, Frederic (2005). "Estrategias y técnicas de traducción para el ajuste o adaptación en el doblaje". R. Merino, J.M. Santamaría. \& E. Pajares E. (eds) (2005). Trasvases Culturales: Literatura, Cine, Traducción, 4, 145-153.

Chaves, María José (2000). La traducción cinematográfica. El doblaje. Huelva: Publicaciones de la Universidad de Huelva.

Delabastita, Dirk (1990). "Translation and the Mass Media”. S. Bassnett \& A. Lefevere (eds) (1990). Translation, History and Culture London. New York: Pinter, 97-109.

Goris, Oliver (1993). “The Question of French Dubbing: Towards a Frame for Systematic Investigation". Target, 5 (2), 169-190.

Hermans, Theo (1985). The Manipulation of Literature. Studies in Literary Translation. London; Sidney: Croom Helm.

Hermans, Theo (1999). Translation in Systems. Manchester: St. Jerome Publishing.

Hurtado, Amparo (2001). Traducción y traductología. Madrid: Cátedra.

Karamitroglou, Fotios (2000). Towards a Methodology for the Investigation of Norms in Audiovisual Translation. Amsterdam: Rodopi.,

Marco Borillo, Josep. (2004). "Les tècniques de traducció (dels referents culturals): retorn per a quedar-nos-hi”. Quaderns. Revista de traducció, 11, pp. 129-149.

Martí Ferriol, José Luis (2003). Estudio descriptivo y comparativo de las normas de traducción en las versiones doblada y subtitulada del filme "Monsters' Ball” (inglés-español). Research project. Universitat Jaume I, Castelló.

Martí Ferriol, José Luis (2006). Estudio empírico y descriptivo del método de traducción para doblaje y subtitulación. PhD thesis. Universitat Jaume I, Castelló. http://www.tesisenxarxa.net/TDX-1122106-122044/

Mayoral, Roberto, Kelly, Dorothy and Gallardo, Natividad (1988). “'Concept of Constrained Translation. Non-Linguistic Perspectives of Translation”. Meta XXXIII (3), 356-367. 
Munday, Jeremy. (2001). Introducing Translation Studies. Theories and Applications. London; New York: Routledge.

Titford, Cristopher (1982). "Subtitling - Constrained Translation". Lebende Sprachen XXVII (3), $113-116$

Toury, Gideon (1980). In Search of a Theory of Translation. The Porter Institute for Poetics and Semiotics: Tel Aviv University.

Toury, Gideon (1995). Descriptive Translation Studies and Beyond. Amsterdam/Philadelphia: John Benjamins.

Venuti, Lawrence (1995). The Translator's Invisibility. London/New York: Routledge.

Whitman, Candance (1992). Through the Dubbing Glass. Frankfurt: Peter Lang.

Zabalbeascoa, Patrick (1996). "La traducción de la comedia televisiva: implicaciones teóricas".

J.M. Bravo \& P. Fernández Nistal (eds) (1996). A Spectrum of Translation Studies. Valladolid: Universidad de Valladolid, 173-201.

\section{Filmography}

Monsters' Ball (2001)

USA/Canada

Dir. Marc Foster

In the Bedroom (2001)

USA

Dir. Todd Field

The Hours (2002)

USA
Dir. Stephen Daldry

\section{Elephant (2003)}

USA

Dir. Gus van Sant

Lost in Translation (2003)

USA/Japan

Dir. Sophia Coppola

1 Refer to Martí Ferriol, 2006, chapter 6.

2 Hermans (1999) makes this aspect clear, in the sense that it could look like a contradiction to study norms from a descriptive approach.

3 An empirical and descriptive research project in audiovisual translation.

4 Refer to Martí Ferriol, 2006, chapter 9, for a complete revision of results. 